Supporting Information

\title{
Enzymatic Plasticity Inspired by the Diterpene Cyclase CotB2
}

Xiaowen Tang ${ }^{1,2}$, Fan Zhang ${ }^{1}$, Tao Zeng ${ }^{1}$, Wei $\mathrm{Li}^{1}$, Sheng $\mathrm{Yin}^{1 *}$ and Ruibo $\mathrm{Wu}^{1 *}$

${ }^{1}$ Guangdong Provincial Key Laboratory of New Drug Design and Evaluation, School of Pharmaceutical Sciences, Sun Yat-sen University, Guangzhou 510006, China

${ }^{2}$ Department of Medicinal Chemistry, School of Pharmacy, Qingdao University, Qingdao 266021, China

${ }^{*}$ To whom correspondence should be addressed.

Sheng Yin: yinsh2@mail.sysu.edu.cn;Ruibo Wu:wurb3@mail.sysu.edu.cn

\section{Table of contents}

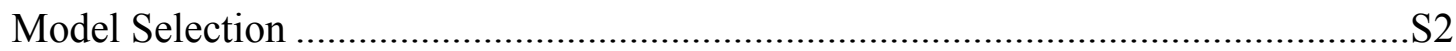

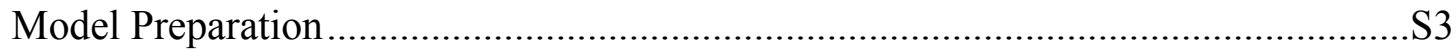

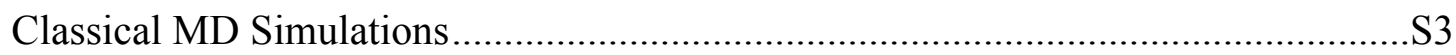

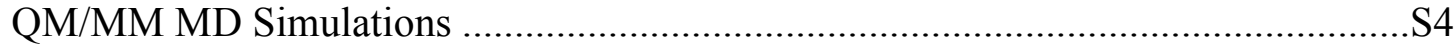

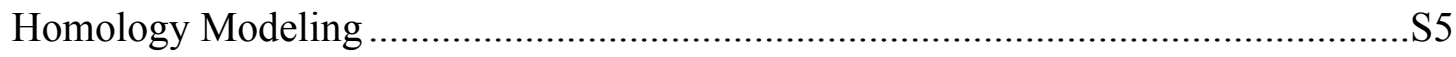

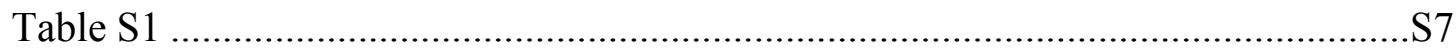

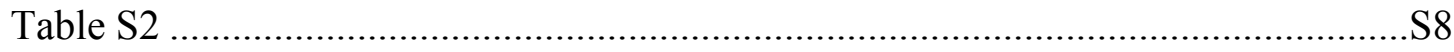

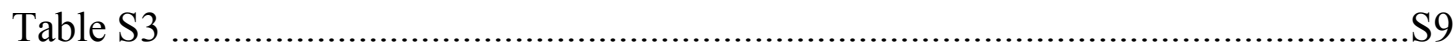

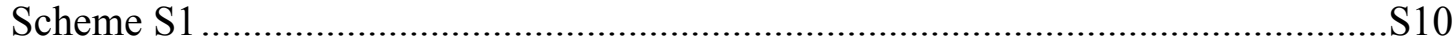

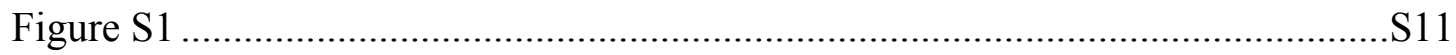

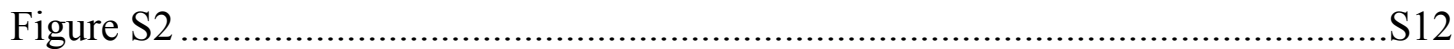

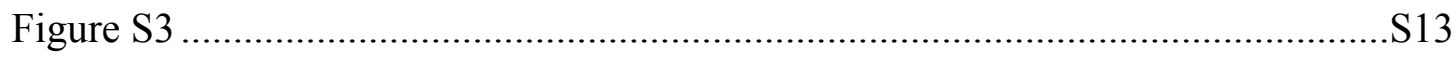

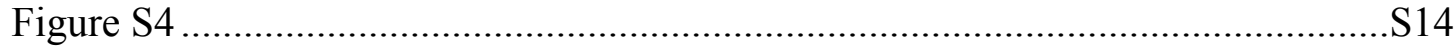

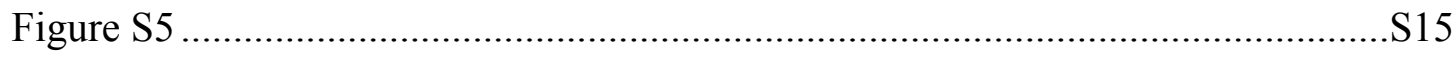

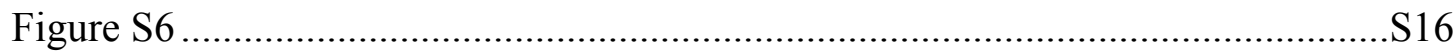

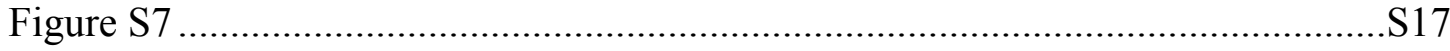

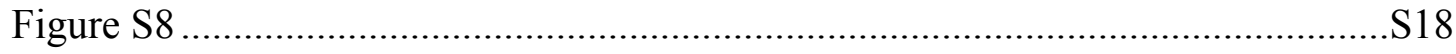

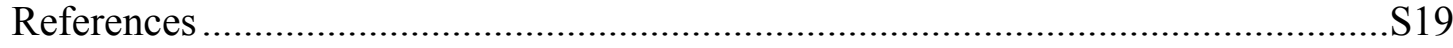




\section{Model Selection}

Available crystal structures of CotB2 are collected and summarized in Table S3. The structure of 5GUE is supposed to be the most suitable model for simulating the CotB2-catalyzed cascade, as the high resolution and a complete substrate analogue GGSPP. ${ }^{1}$ However, there are still some fatal defects that severely limited an overall simulation from GGPP to cyclooctat-9-en-7-ol. For example, the incompletion of trinuclear magnesium cluster and C-terminal region lead to an incomplete structure or pre-catalytic conformation, which can be modified by transferring from the homology model to some extent. But for the substrate configuration, we have found that the substrate analogue GGSPP is provided with an inaccuracy configuration as displayed in Figure S7. The natural substrate GGPP in CotB2 is known as an all-trans isomer (2E,6E,10E-GGPP), but it is crystallized as a $2 E, 6 Z, 10 E-G G P P$ isomer, which provides a confused and invalid folding model in the active site. ${ }^{1,2}$ The high flexibility of GGPP makes it be challenging to adopt molecular docking, even we construct the proper GGPP isomer. An effective solution is reducing the flexibility by using a cyclic intermediate. In fact, it is the various reactive modes of the carbocation intermediate instead of the ionization of GGPP that forms the diversity of terpene skeletons. Besides, ionization of GGPP is identified as a conventional step in class I terpene cyclase catalysis, which is greatly dependent on the trigger action of trinuclear metal cluster and a fully closed catalytic conformation. ${ }^{3}$ In contrast, the subsequent cyclization of carbocation intermediate occurs more easily as its extremely high reactivity. In this context, investigating ionization of GGPP is unattractive with slight significance and may be impeded by some defects in the selected model. Therefore, our present investigation mainly focused on the cyclization of carbon skeleton, without regard to the universal step of initial C-O bond cleavage.

When the current study is almost finished, a new co-crystal structure with intermediate analogue F-Dola binding in the active site is reported (PDB entry: 6GGI), in which the trinuclear magnesium cluster and C-terminal region are more complete. ${ }^{4}$ Previous study reported that crystal structure of the two models (5GUE and 6GGI) 
matches perfectly with the main chain root mean square deviation (RMSD) of only about $0.8 \AA .{ }^{4}$ Even so, we still conducted some prudential comparative studies to further demonstrate the reliability of our current study. With $50 \mathrm{~ns}$ molecular dynamics (MD) simulation, the two structures are stable and highly consistent with RMSD less than 1.4 $\AA ̊$ (see Figure S8a). Furthermore, we perform QM/MM calculation to probe the reaction energy barrier of the first 1,5-hydride shift by using the model from 6GGI. A total of three initial models were selected randomly from the equilibrious structures from MD trajectory. The QM/MM prediction shows consistency between 6GGI and 5GUE models as shown in Figure S8b. All these benchmark and comparative tests have confirmed the reliability of our computational model.

\section{Model Preparation}

When constructing our computational model, the protonation states of titratable residues were estimated through $\mathrm{H}++$ program, and their individual local hydrogen bond networks were carefully examined. ${ }^{5}$ For the catalytic substrate, ionization of GGPP was completed manually by breaking the $\mathrm{C}-\mathrm{O}$ bond, then the pyrophosphate group and its coordination mode with $\mathrm{Mg}^{2+}$ ions were maintained and the hydrocarbon fragment was deleted. Referring to the previous researches ${ }^{1,2,4,6-8}$, we constructed the carbocation intermediate $\mathbf{A}$ which was subsequently docked into the active site of our enzyme model with careful visual inspections. Eventually, the constructed model was used for the following classical molecular dynamics (MD) and QM/MM simulations.

\section{Classical MD Simulations}

All simulations were performed by using AMBER12 molecular simulation package. ${ }^{9}$ The Amber ff99SB force field ${ }^{10}$ was employed for the protein and the TIP3P model $^{11}$ was used for solvent water molecules. The force field parameters of carbocation intermediate $\mathbf{A}$ and pyrophosphate group were generated from the general AMBER force field (GAFF) ${ }^{12}$, and the partial atomic charges of them were defined by the restrained electrostatic potential (RESP) charge ${ }^{13}$ based on $\mathrm{HF} / 6-31 \mathrm{G}^{*}$ calculation with the Gaussian 09 package $^{14}$. The reliability of the parameter fitting procedure for 
the ligand was demonstrated in our previous studies. ${ }^{15}$ The initial coordinates and topology files were generated by the tleap program $^{9}$ with neutralization and solvation. The subsequent classical MD simulations were carried out by using the periodic boundary condition with cubic model. The routine minimization, first by constraining all solute atoms then protein backbone and finally no constraint, were carried out to preliminarily relax the solvent and protein-ligand complex. After the optimization, the system was heated from 0 to $300 \mathrm{~K}$ gradually under the NVT ensemble for $100 \mathrm{ps,}$ followed by another 100 ps NPT ensemble MD simulations at $300 \mathrm{~K}$ and the target pressure of $1.0 \mathrm{~atm}$. Afterward, $50 \mathrm{~ns}$ NVT production MD simulations with a target temperature of $300 \mathrm{~K}$ were performed to produce trajectories. During the MD simulations, the SHAKE algorithm ${ }^{16}$ was applied to constrain the high-frequency stretching vibration of all hydrogen-containing bonds, and a cutoff of $12 \AA$ was set for both van der Waals (LJ-12 potential) and electrostatic interactions (PME strategy). Finally, the last snapshot from the stable MD trajectory was chosen to build the initial model for the subsequent QM/MM simulations.

\section{QM/MM MD Simulations}

All QM/MM calculations were performed with the modified QChem ${ }^{17}$ and Tinker $^{18}$ programs. The initial QM/MM model was prepared by deleting the solvent molecules beyond $25 \AA$ from the $\mathrm{C} 1$ atom of carbocation intermediate A. The carbocation intermediate and pyrophosphate group together with $\mathrm{Mg}^{2+}$ ions were considered in QM region undoubtedly, the residue of Phe107 was also considered as it can stabilize the carbocation intermediate. To balance the computational accuracy and cost, the selection of other amino acid residues was depended on the reaction steps. For example, to better consider the dipole-dipole interactions in the hydride shift from $\mathbf{A}$ to $\mathbf{B} / \mathbf{B}^{\prime}$, Asn 103 and Asn285 were treated in QM region, and to better consider the interaction between the electron-rich (aromatic) residue and the carbocation, Trp186 was also considered in it. The rest atoms were considered in the MM region. In the subsequent steps, these residues were removed from the QM area as the hydride shift is completed and the cation migrates far from Trp186. All the QM atoms were described with M06-2X 19,20 
in combination with the 6-31G(d) basis set which is widely used in studying cyclization reaction, ${ }^{21-25}$ and each model contains about 800 basis functions in total. The QM/MM boundary was treated by the improved pseudo-bond approach ${ }^{26-28}$. The same molecular mechanical force field as in the previous classical MD simulation was used for all of the remaining atoms. The spherical boundary condition was employed, and atoms more than $25 \AA$ away from the spherical center were fixed. The $12 \AA$ and $18 \AA$ cutoffs were employed for van der Waals and electrostatic interactions, respectively. There was no cutoff for electrostatic interactions between $\mathrm{QM}$ and $\mathrm{MM}$ regions. The $\mathrm{QM} / \mathrm{MM}$ system was minimized again for several iterations, and more than 5 ps QM/MM MD simulations were performed. The resulting conformation was used to map out the minimum energy path with the reaction coordinate (RC) driving method ${ }^{29}$ according to the reaction coordinates defined as shown in Scheme S1. After that, the MM region was further equilibrated by 500 ps free energy perturbation (FEP) simulations, with QM region fixed at previously $\mathrm{QM} / \mathrm{MM}$ minimized structures. Finally, the resulting snapshots were treated as the starting structures for biased-potential based QM/MM MD umbrella sampling ${ }^{30}$. The system temperature was controlled by the Langevin thermostat method ${ }^{31}$ at $300 \mathrm{~K}$ and the Newton equations of motion were integrated by the Beeman algorithm ${ }^{32}$. More than 100 windows were partitioned along the reaction path and each window was calculated for at least 20 ps with $1 \mathrm{fs}$ time step, as a result, in total about 2.0 ns ab initio QM/MM MD simulations were carried out to characterize the overall reaction of CotB2-catalyzed cascade. The overlap of histogram between neighboring windows were checked to confirm if each window were adequately sampled along the proper reaction coordinate, and then WHAM program ${ }^{33,34}$ was employed to calculate the free energy profile. The convergence of QM/MM MD umbrella sampling can be estimated by the free energy profile gap calculated from different time spans. This free energy calculation protocols are successfully utilized and validated in our previous studies. ${ }^{21-25}$

When simulating the carbocation quenching process simulated in aqueous phase, carbocation intermediate was saved from $\mathbf{H}$ state of CotB2-catalyzed cyclization 
cascade, then put into a water box with a dimension of $35 \times 35 \times 35 \AA^{3}$. The carbocation intermediate and water molecules within $5 \AA$ of $\mathrm{C} 7 / \mathrm{C} 10$ atom were treated in $\mathrm{QM}$ region and the rest atoms were considered in the MM region. The subsequent MD and QM/MM simulations were adopted with the same settings as the enzyme model. The defined reaction coordinates (RC) are shown in Scheme S1.

\section{Homology Modeling}

The sequence of casbene synthase from Euphorbiaceae was obtained from the Universal Protein Resource (UniProt, Entry: P59287). Homology Model was built by using the SWISS-MODEL protein structure homology-modelling server. ${ }^{35-37}$ The SWISS-MODEL template library (SMTL, last update: 2019-12-12, last included PDB release: 2019-12-06) was searched with BLAST $^{38}$ and HHBlits ${ }^{39}$ for evolutionary related structures matching the target sequence. Overall 203 templates were found with a total of 42 templates were found by BLAST and a total of 161 templates were found by HHblits. At last, the crystal structure of aristolochene synthase (PDB Code: 3M00) was selected as the optimal template, as its high sequence similarity (42\%) and coverage (89\%). The final model is built based on the target-template alignment using ProMod3. The global and per-residue model quality has been assessed using the QMEAN scoring function. ${ }^{40,41}$ Pyrophosphate and $\mathrm{Mg}^{2+}$ ions were transferred from the template structure, the casbene ligand was constructed manually and then docked into the active site with careful visual inspections. Finally, the ligand-bound casbene synthase model was optimized with structure inspection and energy minimization in MOE software. 
Table S1. Summary of previously reported computational data for CotB2-catalyzed reaction cascade from $\mathbf{A}$ to $\mathbf{H}$. Model 1 represents the gas phase model that only contains the carbocation intermediate, and model 2 represents the active site model that contains the carbocation intermediate, pyrophosphate, magnesium ions and some active site residues (N103, T106, F107, F149, I181, W186, N285). ${ }^{6-8}$

\begin{tabular}{ccccc}
\hline $\begin{array}{c}\text { Theoretical } \\
\text { model }\end{array}$ & Method & Basis set & Thermal effect & Reference \\
(kcal mol $\left.\mathbf{~}^{-1}\right)$ & & \\
\hline Model 1 & M062X & $6-31+\mathrm{G}^{* *}$ & -27.8 & Ref. 6 \\
\hline Model 1 & M062X & $6-31 \mathrm{G}^{* *}$ & -43.6 & Ref. 7 \\
\hline Model 1 & B3LYP & $6-31 \mathrm{G}^{*}$ & -37.5 & Ref. 8 \\
\hline Model 1 & mPW1PW91 & $6-31+\mathrm{G}^{* *}$ & -27.9 & Ref. 8 \\
\hline Model 2 & M062X & $6-31+\mathrm{G}^{* *}$ & -40.9 & Ref. 6 \\
\hline
\end{tabular}


Table S2. Reaction heats and barriers (in brackets) for every step in CotB2-catalyzed reaction cascade from $\mathbf{A}$ to $\mathbf{H}$. Model 1 and model 2 are the same meaning as noted in Table S1.

\begin{tabular}{|c|c|c|c|c|c|c|c|c|c|c|c|}
\hline \multirow{2}{*}{$\begin{array}{c}\text { Theoretical } \\
\text { model }\end{array}$} & \multicolumn{2}{|c|}{ Theoretical level } & \multicolumn{8}{|c|}{ Energy (kcal mol-1) } & \multirow{2}{*}{$\begin{array}{c}\text { Referenc } \\
\text { e }\end{array}$} \\
\hline & Method & Basis set & A-B & B-C & C-D & D-E & E-E' & E'-F & F-G & G-H & \\
\hline Model 1 & M062X & $6-31+\mathrm{G}^{* *}$ & $\begin{array}{c}0.1 \\
(7.5)\end{array}$ & $\begin{array}{l}-9.0 \\
(4.3)\end{array}$ & $\begin{array}{l}-2.2 \\
(7.5)\end{array}$ & $\begin{array}{l}-1.6 \\
(2.7)\end{array}$ & \multicolumn{2}{|c|}{$\begin{array}{l}-0.7 \\
(1.1)\end{array}$} & $\begin{array}{l}-9.6 \\
(0.5)\end{array}$ & $\begin{array}{l}-4.9 \\
(5.3)\end{array}$ & Ref. 6 \\
\hline Model 1 & M062X & $6-31 \mathrm{G}^{* *}$ & $\begin{array}{l}-0.5 \\
(6.0)\end{array}$ & $\begin{array}{l}-7.8 \\
(5.5)\end{array}$ & $\begin{array}{l}-1.4 \\
(7.1)\end{array}$ & $\begin{array}{l}-2.2 \\
(1.4)\end{array}$ & $\begin{array}{l}-2.4 \\
(1.7)\end{array}$ & $\begin{array}{c}2.4 \\
(4.0)\end{array}$ & $\begin{array}{l}-10.1 \\
(1.4)\end{array}$ & $\begin{array}{l}-4.3 \\
(6.5)\end{array}$ & Ref. 7 \\
\hline Model 1 & B3LYP & $6-31 G^{*}$ & $\begin{array}{l}-5.9 \\
(3.4)\end{array}$ & $\begin{array}{l}-9.9 \\
(3.1)\end{array}$ & $\begin{array}{l}-4.5 \\
(2.3)\end{array}$ & $\begin{array}{l}-6.1 \\
(3.4)\end{array}$ & $\begin{array}{c}2.5 \\
(6.9)\end{array}$ & $\begin{array}{l}-0.4 \\
(0.1)\end{array}$ & $\begin{array}{l}-4.9 \\
(1.1)\end{array}$ & $\begin{array}{l}-6.7 \\
(9.4)\end{array}$ & Ref. 8 \\
\hline Model 1 & mPW1PW91 & $6-31+\mathrm{G}^{* *}$ & $\begin{array}{l}-5.4 \\
(4.8)\end{array}$ & $\begin{array}{l}-3.1 \\
(6.5)\end{array}$ & $\begin{array}{l}-4.1 \\
(3.1)\end{array}$ & $\begin{array}{l}-6.7 \\
(4.3)\end{array}$ & $\begin{array}{c}4.8 \\
(7.4)\end{array}$ & $\begin{array}{l}-1.9 \\
(0.1)\end{array}$ & $\begin{array}{l}-3.4 \\
(1.4)\end{array}$ & $\begin{array}{c}-5.6 \\
(15.0)\end{array}$ & Ref. 8 \\
\hline Model 2 & M062X & $6-31+G^{* *}$ & $\begin{array}{l}-14.2 \\
(4.7)\end{array}$ & $\begin{array}{l}-15.7 \\
(2.4)\end{array}$ & $\begin{array}{c}1.9 \\
(3.5)\end{array}$ & $\begin{array}{c}0.2 \\
(9.4)\end{array}$ & & $\begin{array}{c}-9.4 \\
(10.9)\end{array}$ & & $\begin{array}{l}-3.8 \\
(8.4)\end{array}$ & Ref. 6 \\
\hline
\end{tabular}


Table S3. Summary of available crystal structures for CotB2.

\begin{tabular}{|c|c|c|c|c|}
\hline PDB entry & Ligand & Resolution $(\AA)$ & Mutant & Missing Residues \\
\hline \multirow{2}{*}{ 4OMG } & \multirow{2}{*}{ l } & \multirow{2}{*}{1.64} & \multirow{2}{*}{ l } & $1-15,296-318$ (Chain A) \\
\hline & & & & 1-13, 293-318 (Chain B) \\
\hline \multirow{2}{*}{ 4ОМН } & \multirow{2}{*}{ / } & \multirow{2}{*}{1.64} & \multirow{2}{*}{ F149L } & $1-12,293-318$ (Chain A) \\
\hline & & & & $1-12,295-318$ (Chain B) \\
\hline 5GUC & / & 1.80 & l & 1-11, 293- 318 (Chain A\&B) \\
\hline 5GUE & GGSPP & 1.80 & / & 1-11, 297-318 (Chain A\&B) \\
\hline \multirow{2}{*}{ 6GGI } & PPi & \multirow{2}{*}{1.80} & \multirow{2}{*}{ / } & $1-13,308-318$ (Chain A) \\
\hline & F-Dola & & & 1-8, 309-318 (Chain B) \\
\hline \multirow{2}{*}{ 6GGJ } & \multirow{2}{*}{$\mathrm{PPi}$} & \multirow{2}{*}{2.10} & \multirow{2}{*}{ / } & $1-15,299-318$ (Chain A) \\
\hline & & & & $1-12,309-318$ (Chain B) \\
\hline \multirow{2}{*}{ 6GGK } & \multirow{2}{*}{ / } & \multirow{2}{*}{2.15} & \multirow{2}{*}{ / } & $1-15,294-318$ (Chain A) \\
\hline & & & & $1-15,293-318$ (Chain B) \\
\hline \multirow{2}{*}{ 6GGL } & \multirow{2}{*}{ / } & \multirow{2}{*}{1.90} & \multirow{2}{*}{ F107A } & $1-14,292-318$ (Chain A) \\
\hline & & & & $1-11,292-318$ (Chain B) \\
\hline
\end{tabular}



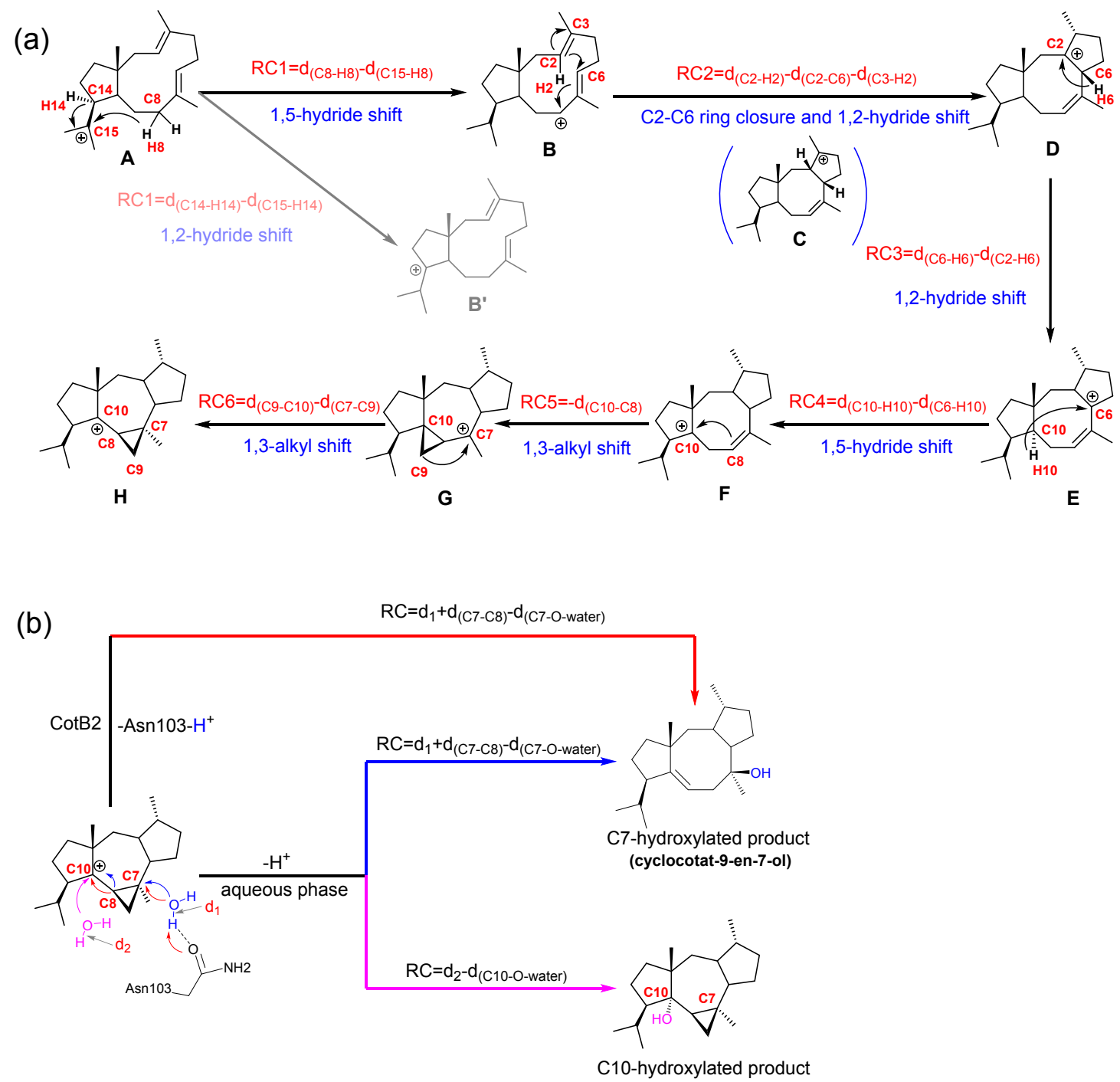

Scheme S1. The defined reaction coordinates (RC) for CotB2-catalyzed cyclization cascade (a) and the final carbocation quenching process simulated in enzyme and aqueous phase (b). 
(a)

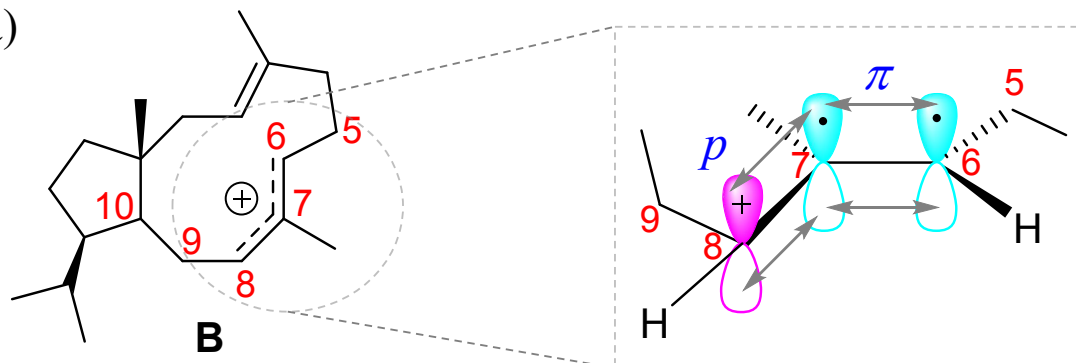

(b)

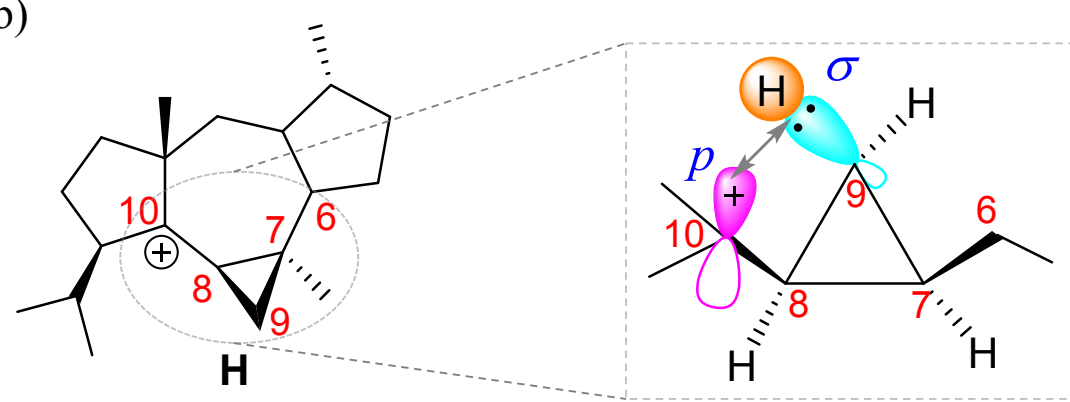

Figure S1. (a) Internal $p-\pi$ conjugation in intermediate $\mathbf{B}$ and (b) internal $\sigma-p$ hyperconjugation in intermediate $\mathbf{H}$. 


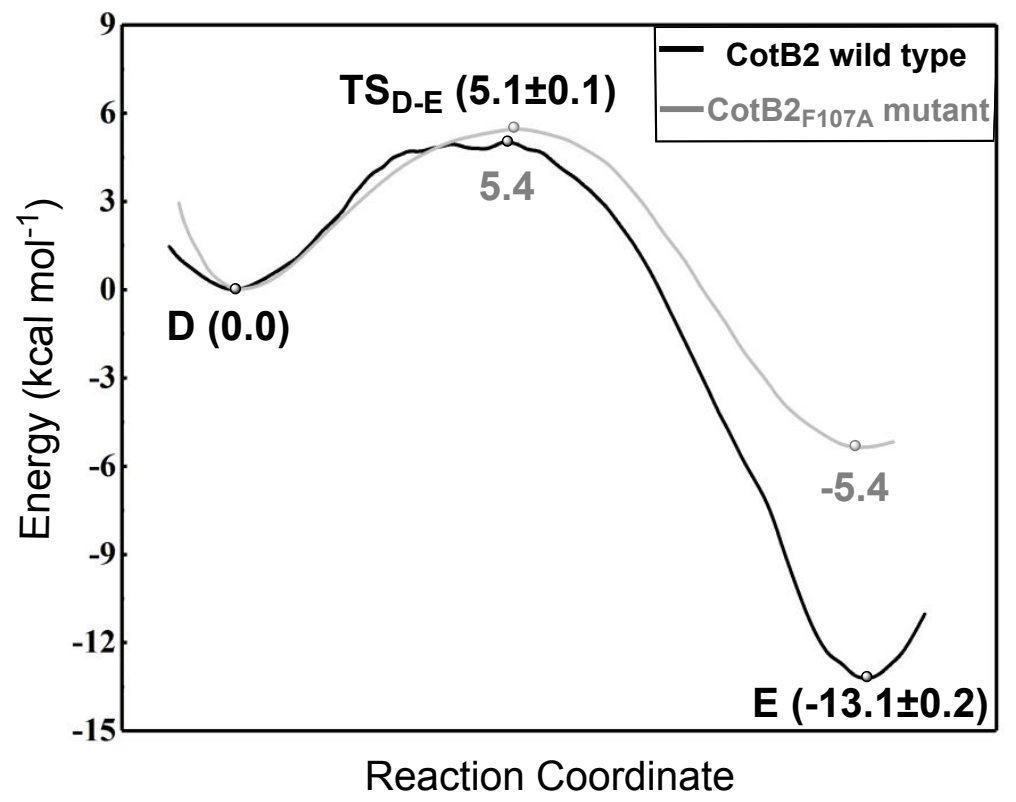

Figure S2. Energy profiles for the second 1,2-hydride shift (intermediate $\mathbf{D}$ to $\mathbf{E}$ ) in CotB2 wild type and CotB2 ${ }_{F 107 A}$ mutant model. 


\begin{tabular}{lcccccccc}
\hline & 80 & 103 & 107 & 110 & 111 & 112 & 113 \\
CotB2 (C20) & V & N & F & D & D & M & D \\
PaFS (C20) & F & N & F & D & D & V & T & D \\
CgDS (C20) & V & S & F & D & D & L & T & D \\
\hline PbSS (C25) & F & C & F & D & D & V & T & D \\
EvQS (C25) & V & T & F & D & D & Y & Y & D \\
AcOS (C25) & F & L & F & D & D & V & I & D \\
PvPS (C25) & G & N & F & D & D & I & L & D \\
\hline
\end{tabular}

Figure S3. Sequence alignment of some type-B cyclopentane-forming terpene synthases. 


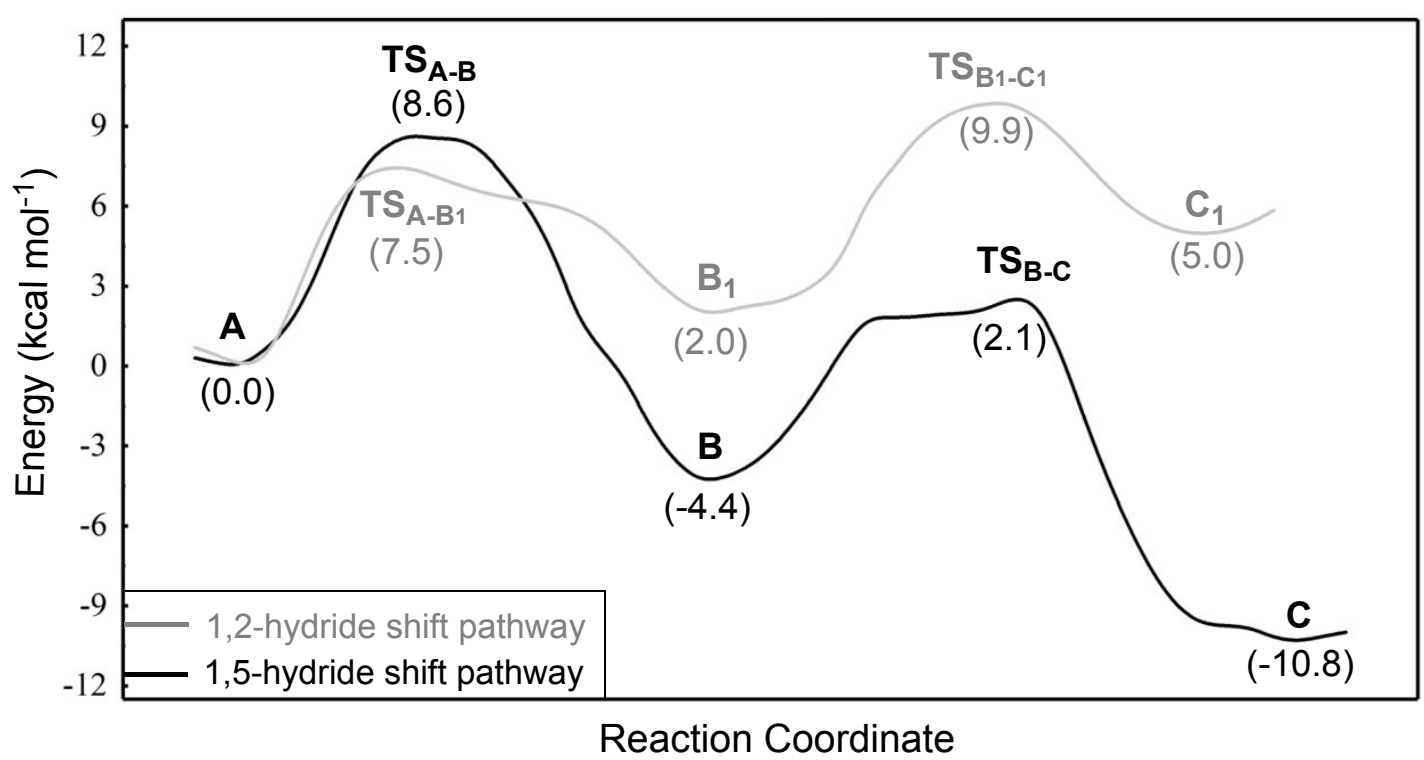

Figure S4. Energy profile for the two types of hydride shift proceed in intermediate A. 


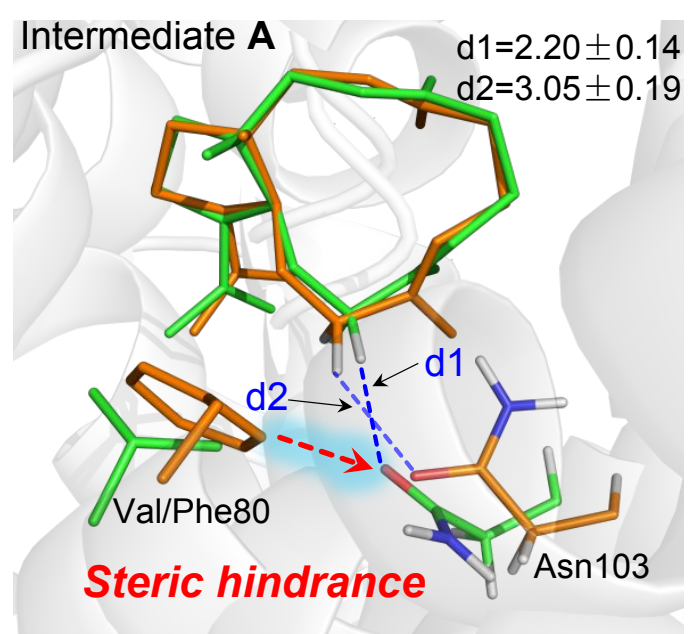

(a)

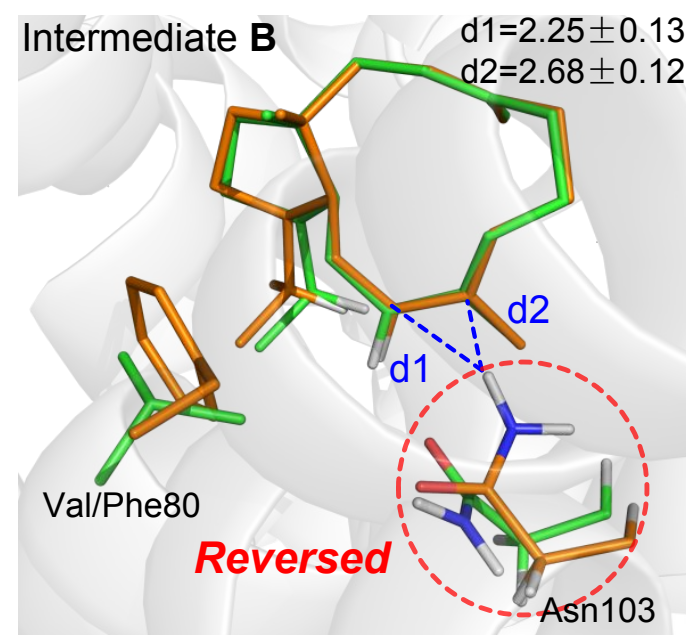

(b)

Figure S5. Structural comparison of intermediate A (a) and $\mathbf{B}(\mathrm{b})$ in CotB2 wild type (green) and the $\operatorname{CotB} 2_{\mathrm{V} 80 \mathrm{~F}}$ mutant (orange). The key distances are given in $\AA$. The amide group of Asn 103 is deflected on account of steric hindrance and electrical repulsion of the phenyl group of Phe80. In consequence, the nucleophilic carbonyl group moves away from $\mathrm{C} 8$, instead the $\mathrm{N}-\mathrm{H} \sigma$-bond of amino group orients to the electron-deficient segment of carbocation intermediate. The destruction of dipole-dipole interaction between Asn103 and C8 is responsible for the kinetic infeasibility and the electrical repulsion accounts for the thermodynamic instability, for 1,5-hydride shift pathway in CotB2 ${ }_{\mathrm{V} 80 \mathrm{~F}}$ reaction model. 


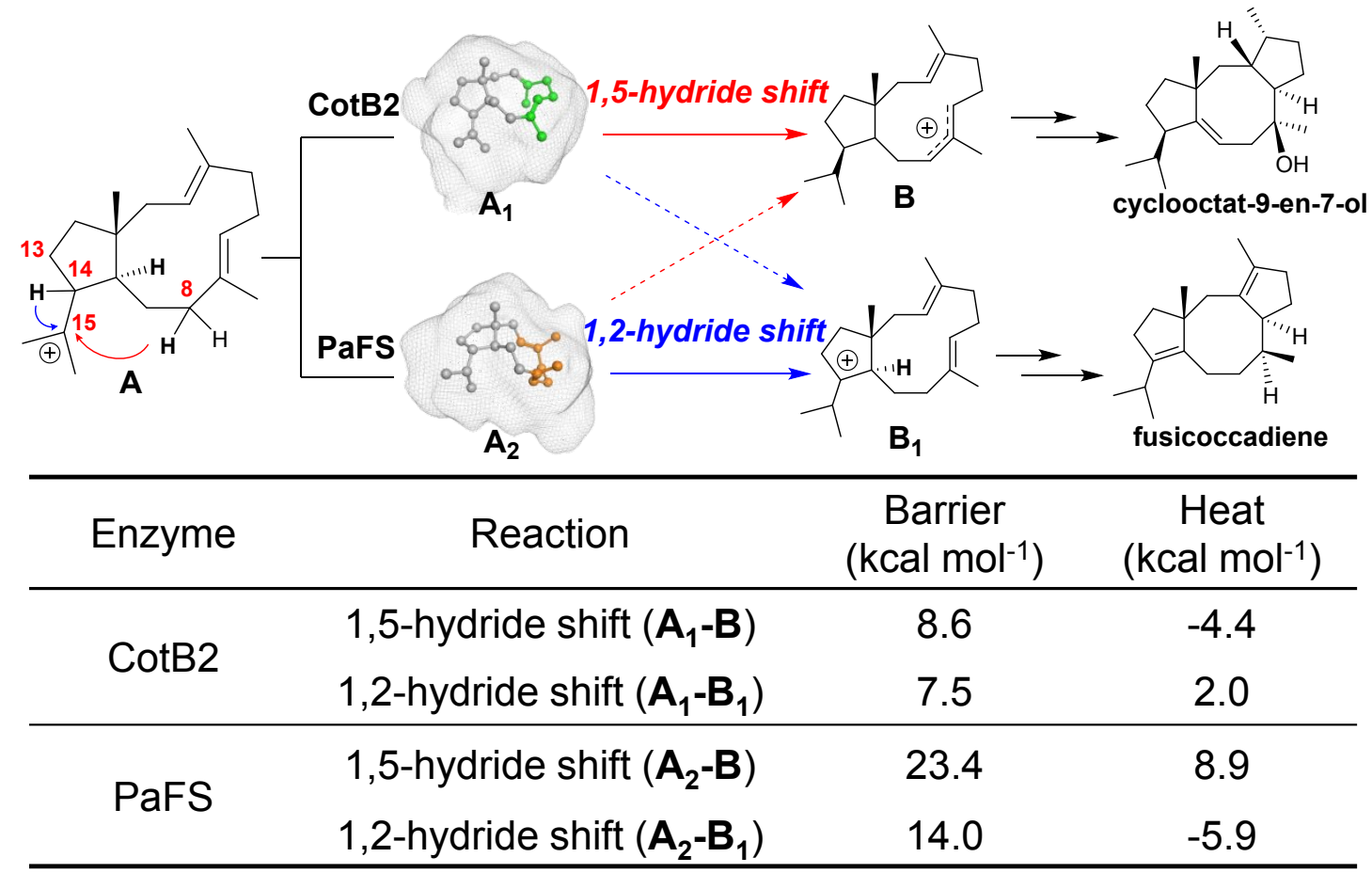

Figure S6. Energetic data for the possible 1,2/1,5-hydride shift of $\mathbf{A}_{\mathbf{1}}$ and $\mathbf{A}_{\mathbf{2}}$. In CotB2, the 1,5-hydride shift from conformer $\mathbf{A}_{\mathbf{1}}$ has been proved as a thermodynamically favored reaction pathway. But in PaFS, the 1,5-hydride shift from conformer $\mathbf{A}_{\mathbf{2}}$ is blocked owing to the high barrier $\left(23.4 \mathrm{kcal} \mathrm{mol}^{-1}\right)$, instead it adopts the 1,2-hydride shift pathway with a moderate barrier $\left(14.0 \mathrm{kcal} \mathrm{mol}^{-1}\right)$. 


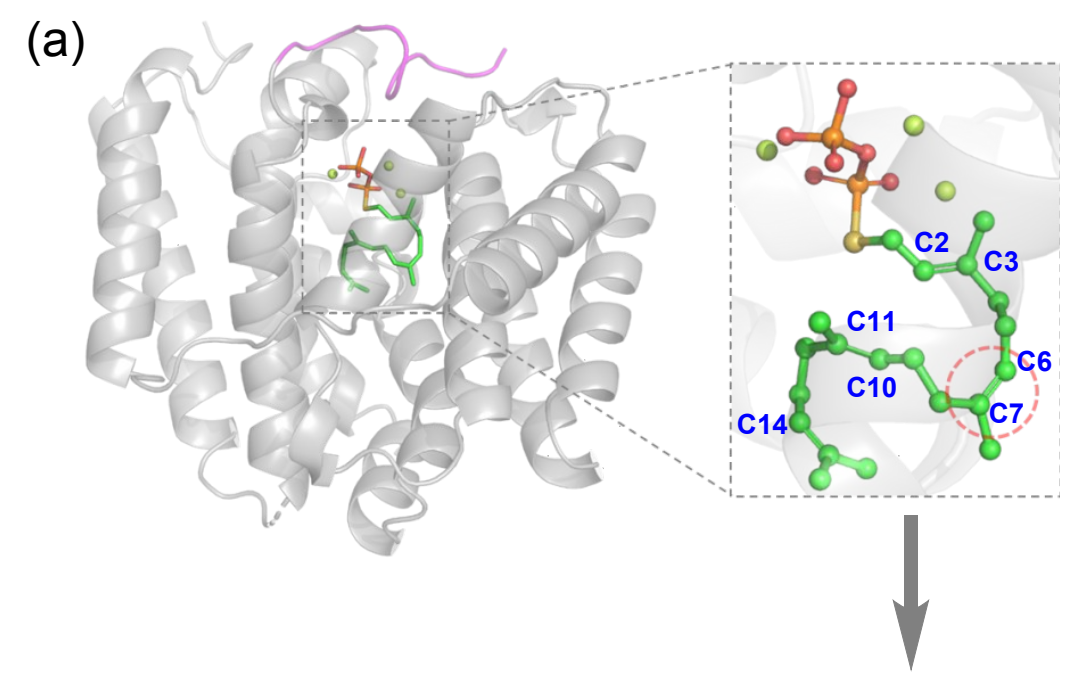

(b)

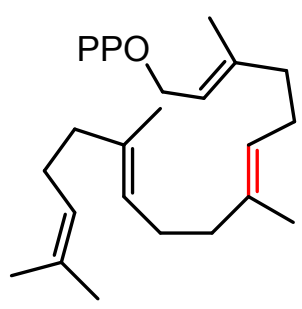

2E,6E,10E-GGPP

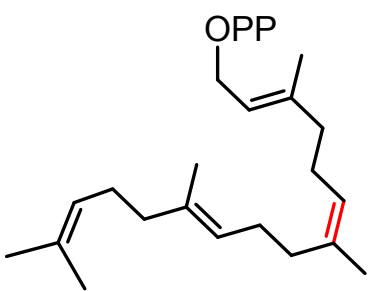

2E,6Z,10E-GGPP

Figure S7. (a) Structure of CotB2 (PDB entry: 5GUE). The C-terminal loop (colored by carmine) and trinuclear magnesium cluster (colored by lime) are missing in the original PDB structure, and thus we restored them for modelling. (b) Two isomers of GGPP $(2 E, 6 E, 10 E$-GGPP and 2E,6Z,10E-GGPP). Different cis-trans are labeled in red. 


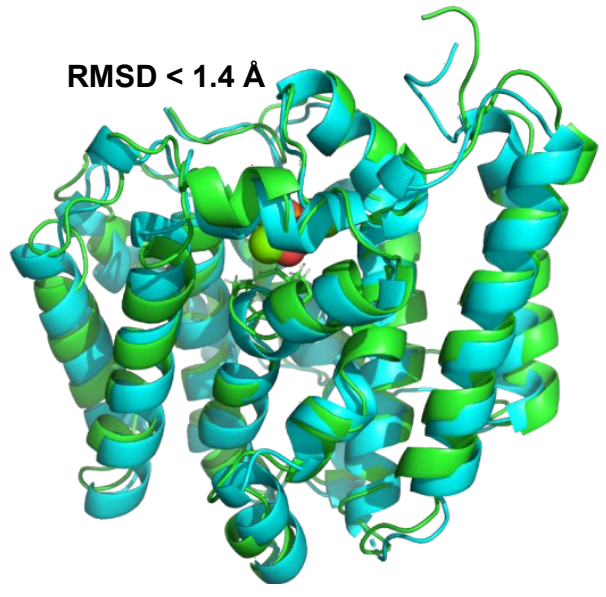

(a)

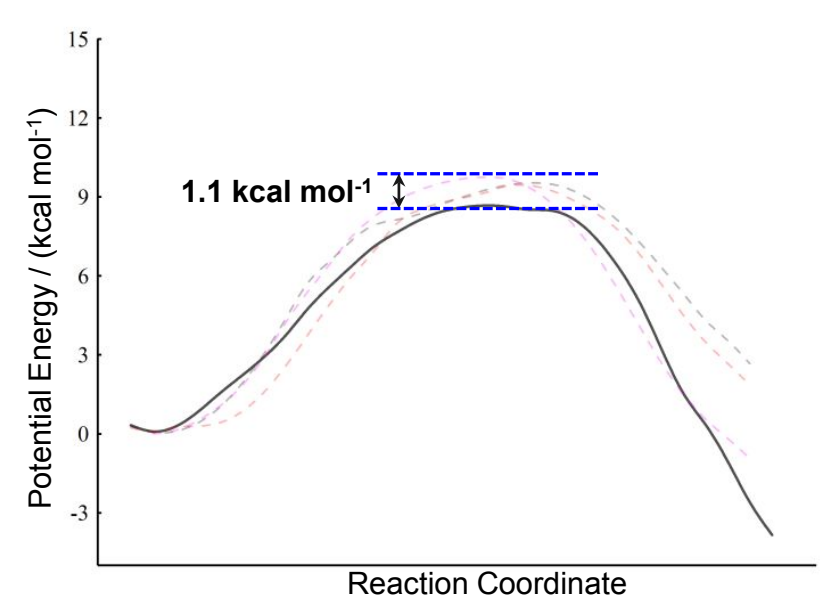

(b)

Figure S8. (a) Structural superposition of 5GUE (cyan) and 6GGI (green) after MD simulation. (b) Energy profiles for 1,5-hydride shift in test models (dashed line) and the computational model (solid line). 


\section{References}

1. Tomita, T.; Kim, S. Y.; Teramoto, K.; Meguro, A.; Ozaki, T.; Yoshida, A.; Motoyoshi, Y.; Mori, N.; Ishigami, K.; Watanabe, H.; Nishiyama, M.; Kuzuyama, T., Structural Insights into the CotB2-Catalyzed Cyclization of Geranylgeranyl Diphosphate to the Diterpene Cyclooctat-9-en-7ol. ACS Chem Biol 2017, 12 (6), 1621-1628.

2. Janke, R.; Gorner, C.; Hirte, M.; Bruck, T.; Loll, B., The first structure of a bacterial diterpene cyclase: CotB2. Acta Crystallogr D Biol Crystallogr 2014, 70 (Pt 6), 1528-37.

3. Aaron, J. A.; Christianson, D. W., Trinuclear Metal Clusters in Catalysis by Terpenoid Synthases. Pure Appl Chem 2010, 82 (8), 1585-1597.

4. Driller, R.; Janke, S.; Fuchs, M.; Warner, E.; Mhashal, A. R.; Major, D. T.; Christmann, M.; Bruck, T.; Loll, B., Towards a comprehensive understanding of the structural dynamics of a bacterial diterpene synthase during catalysis. Nat Commun 2018, 9 (1), 3971.

5. Gordon, J. C.; Myers, J. B.; Folta, T.; Shoja, V.; Heath, L. S.; Onufriev, A. J. N. a. r., H++: a server for estimating $\mathrm{pK}_{\mathrm{a}} \mathrm{s}$ and adding missing hydrogens to macromolecules. 2005, 33 (suppl_2), W368-W371.

6. Raz, K.; Driller, R.; Brück, T.; Loll, B.; Major, D. T. J. B. A., Understanding the Role of Active Site Residues in CotB2 Catalysis Using a Cluster Model. Beilstein Archives. 2019, 2019 (1), 108.

7. Sato, H.; Teramoto, K.; Masumoto, Y.; Tezuka, N.; Sakai, K.; Ueda, S.; Totsuka, Y.; Shinada, T.; Nishiyama, M.; Wang, C.; Kuzuyama, T.; Uchiyama, M., "Cation-Stitching Cascade": exquisite control of terpene cyclization in cyclooctatin biosynthesis. Sci Rep. 2015, 5, 18471.

8. Hong, Y. J.; Tantillo, D. J., The energetic viability of an unexpected skeletal rearrangement in cyclooctatin biosynthesis. Org Biomol Chem 2015, 13 (41), 10273-8.

9. Case, D. A. D., T. A.; Cheatham, T. E., III; Simmerling, C.; L.; Wang, J. D., R. E.; Luo, R.; Walker, R. C.; Zhang, W.; Merz, K.; M.; Roberts, B. H., S.; Roitberg, A.; Seabra, G.; Swails, J.; Goetz, A.; W.; Kolossvary, I. W., K. F.; Paesani, F.; Vanicek, J.; Wolf, R. M.; Liu, J. W., X.; Brozell, S. R.; Steinbrecher, T.; Gohlke, H.; Cai, Q.; Ye,; X.; Wang, J. H., M. J.; Cui, G.; Roe, D. R.; Mathews, D. H.; Seetin,; M. G.; Salomon-Ferrer, R. S., C.; Babin, V.; Luchko, T.; Gusarov,; S.; Kovalenko, A. K., P. A., AMBER12; University of California, San Francisco, CA, 2012.

10. Duan, Y.; Wu, C.; Chowdhury, S.; Lee, M. C.; Xiong, G.; Zhang, W.; Yang, R.; Cieplak, P.; Luo, R.; Lee, T., A point-charge force field for molecular mechanics simulations of proteins based on condensed-phase quantum mechanical calculations. Journal of computational chemistry 2003, 24 (16), 1999-2012.

11. Jorgensen, W. L.; Chandrasekhar, J.; Madura, J. D.; Impey, R. W.; Klein, M. L., Comparison of simple potential functions for simulating liquid water. The Journal of Chemical Physics 1983, 79 (2), 926-935.

12. Wang, J.; Wolf, R. M.; Caldwell, J. W.; Kollman, P. A.; Case, D. A., Development and testing of a general amber force field. Journal of computational chemistry 2004, 25 (9), 1157-74.

13. Bayly, C. I.; Cieplak, P.; Cornell, W.; Kollman, P. A., A well-behaved electrostatic potential based method using charge restraints for deriving atomic charges: the RESP model. The Journal of Physical Chemistry 1993, 97 (40), 10269-10280.

14. Frisch, M. J. T., G. W.; Schlegel, H. B.; Scuseria, G. E.; Robb, M. A. C., J. R.; Scalmani, G.; Barone, V.; Mennucci,; B.; Petersson, G. A. N., H.; Caricato, M.; Li, X.; Hratchian, H.; P.; Izmaylov, A. F. B., J.; Zheng, G.; Sonnenberg, J. L.; Hada, M.; Ehara, M. T., K.; Fukuda, R.; Hasegawa, J.; Ishida, M.; Nakajima,; T.; Honda, Y. K., O.; Nakai, H.; Vreven, T.; Montgomery, J. A., Jr.; Peralta, J. E. O., F.; Bearpark, M.; Heyd, J. J.; Brothers, E.; Kudin,; K. N.; Staroverov, V. N. K., R.; Normand, 
J.; Raghavachari, K.; Rendell, A. B., J. C.; Iyengar, S. S.; Tomasi, J.; Cossi, M.; Rega,; N.; Millam, J. M. K., M.; Knox, J. E.; Cross, J. B.; Bakken, V.;; Adamo, C. J., J.; Gomperts, R.; Stratmann, R. E.; Yazyev, O.; Austin, A. J. C., R.; Pomelli, C.; Ochterski, J. W.; Martin, R. L.; Morokuma, K. Z., V. G.; Voth, G. A.; Salvador, P.; Dannenberg, J. J. D., S.; Daniels, A. D.; Farkas, O.; Foresman, J. B. O., J. V.; Cioslowski, J.; Fox, D. J., Gaussian 09; Gaussian Inc., Wallingford, CT, 2009.

15. Liu, Z.; Zhou, J.; Wu, R.; Xu, J., Mechanism of Assembling Isoprenoid Building Blocks 1. Elucidation of the Structural Motifs for Substrate Binding in Geranyl Pyrophosphate Synthase. $J$ Chem Theory Comput 2014, 10 (11), 5057-67.

16. Ryckaert, J. P. C.; Ciccotti, G.; Berendsen, H. J. C., Numerical integration of the cartesian equations of motion of a system with constraints: molecular dynamics of n-alkanes. Journal of Computational Physics 1977, 23, 327-341.

17. Shao, Y.; Fusti-Molnar, L. J., Y.; Kussmann, J.; Ochsenfeld C.; Brown, S. T.; Gilbert, A. T.; Slipchenko, L. V.; Levchenko, S. V.; O'Neill, D. P.; DiStasio, R. A.; Lochan, R. C.; Wang, T.; Beran, G. J.; Besley, N. A.; Herbert, J. M.; Lin, C. Y.; Van Voorhis, T.; Chien, S. H.; Sodt, A.; Steele, R. P.; Rassolov, V. A.; Maslen, P. E.; Korambath, P. P.; Adamson, R. D.; Austin, B.; Baker, J.; Byrd, E. F.; Dachsel, H.; Doerksen, R. J.; Dreuw, A.; Dunietz, B. D.; Dutoi, A. D.; Furlani, T. R.; Gwaltney, S. R.; Heyden, A.; Hirata, S.; Hsu, C. P.; Kedziora, G.; Khalliulin, R. Z.; Klunzinger, P.; Lee, A. M.; Lee, M. S.; Liang, W.; Lotan, I.; Nair, N.; Peters, B.; Proynov, E. I.; Pieniazek, P. A.; Rhee, Y. M.; Ritchie, J.; Rosta, E.; Sherrill, C. D.; Simmonett, A. C.; Subotnik, J. E.; Woodcock, H. L.; Zhang, W.; Bell, A. T.; Chakraborty, A. K.; Chipman, D. M.; Keil, F. J.; Warshel, A.; Hehre, W. J.; Schaefer, H. F.; Kong, J.; Krylov, A. I.; Gill, P. M.; Head-Gordon, M. , Physical Chemistry Chemical Physics 2006, 8, 3172-3191.

18. Ponder, J. W., TINKER, Software Tools for Molecular Design, version 4.2; Washington University School of Medicine, St. Louis, MO, 2004.

19. Zhao, Y.; Truhlar, D. G., The M06 suite of density functionals for main group thermochemistry, thermochemical kinetics, noncovalent interactions, excited states, and transition elements: two new functionals and systematic testing of four M06-class functionals and 12 other functionals. Theoretical Chemistry Accounts 2008, 120 (1-3), 215-241.

20. Zhao, Y.; Truhlar, D. G., Exploring the Limit of Accuracy of the Global Hybrid Meta Density Functional for Main-Group Thermochemistry, Kinetics, and Noncovalent Interactions. J Chem Theory Comput 2008, 4 (11), 1849-68.

21. Zhang, F.; Chen, N. H.; Zhou, J. W.; Wu, R. B., Protonation-Dependent Diphosphate Cleavage in FPP Cyclases and Synthases. Acs Catalysis 2016, 6 (10), 6918-6929.

22. Chen, N.; Wang, S.; Smentek, L.; Hess, B. A., Jr.; Wu, R., Biosynthetic Mechanism of Lanosterol: Cyclization. Angew Chem Int Ed Engl 2015, 54 (30), 8693-6.

23. Zhou, J. W.; Wang, X. M.; Kuang, M.; Wang, L. Y.; Luo, H. B.; Mo, Y. R.; Wu, R. B., Protonation-Triggered Carbon-Chain Elongation in Geranyl Pyrophosphate Synthase (GPPS). Acs Catalysis 2015, 5 (7), 4466-4478.

24. Zhou, J.; Wu, R.; Wang, B.; Cao, Z.; Yan, H.; Mo, Y., Proton-Shuttle-Assisted Heterolytic Carbon-Carbon Bond Cleavage and Formation. ACS Catalysis 2015, 5 (5), 2805-2813.

25. Wang, Y. H.; Xie, H. J.; Zhou, J. W.; Zhang, F.; Wu, R. B., Substrate Folding Modes in Trichodiene Synthase: A Determinant of Chemo- and Stereoselectivity. Acs Catalysis 2017, 7 (9), 5841-5846.

26. Zhang, Y. K.; Lee, T. S.; Yang, W. T., A pseudobond approach to combining quantum mechanical and molecular mechanical methods. Journal of Chemical Physics 1999, 110 (1), 46-54.

27. Chen, X.; Zhang, Y.; Zhang, J. Z., An efficient approach for ab initio energy calculation of biopolymers. J Chem Phys 2005, 122 (18), 184105.

28. Zhang, Y. K., Pseudobond ab initio QM/MM approach and its applications to enzyme reactions. Theoretical Chemistry Accounts 2006, 116 (1-3), 43-50.

29. Zhang, Y. K.; Liu, H. Y.; Yang, W. T., Free energy calculation on enzyme reactions with an efficient iterative procedure to determine minimum energy paths on a combined ab initio QM/MM potential energy surface. Journal of Chemical Physics 2000, 112 (8), 3483-3492.

30. Torrie, G. M.; Valleau, J. P., Nonphysical sampling distributions in Monte Carlo free-energy estimation: Umbrella sampling. J. Comput. Phys. 1977, 23, 187-199.

31. Davidchack, R. L.; Handel, R.; Tretyakov, M. V., Langevin thermostat for rigid body dynamics. J Chem Phys 2009, 130 (23), 234101.

32. Beeman, D., Some multistep methods for use in molecular dynamics calculations. J. Comput. 
Phys. 1976, 20, 130-139.

33. Kumar, S.; Rosenberg, J. M.; Bouzida, D.; Swendsen, R. H.; Kollman, P. A., THE weighted histogram analysis method for free-energy calculations on biomolecules. I. The method. J. Comput. Chem. 1992, 13, 1011-1021.

34. Souaille, M.; Roux, B., Extension to the weighted histogram analysis method: combining umbrella sampling with free energy calculations. Computer Physics Communications 2001, 135 (1), 40-57.

35. Waterhouse, A., Bertoni, M., Bienert, S., Studer, G., Tauriello, G., Gumienny, R., Heer, F.T., de Beer, T.A.P., Rempfer, C., Bordoli, L., Lepore, R., Schwede, T. SWISS-MODEL: homology modelling of protein structures and complexes. Nucleic Acids Res. 2018, 46, 296-303.

36. Guex, N., Peitsch, M.C., Schwede, T. Automated comparative protein structure modeling with SWISS-MODEL and Swiss-PdbViewer: A historical perspective. Electrophoresis 2009, 30, 162173.

37. Bienert, S., Waterhouse, A., de Beer, T.A.P., Tauriello, G., Studer, G., Bordoli, L., Schwede, T. The SWISS-MODEL Repository - new features and functionality. Nucleic Acids Res. 2017, 45, 313319.

38. Camacho, C., Coulouris, G., Avagyan, V., Ma, N., Papadopoulos, J., Bealer, K., Madden, T.L. BLAST+: architecture and applications. BMC Bioinformatics 2009, 10, 421-430.

39. Remmert, M., Biegert, A., Hauser, A., Söding, J. HHblits: lightning-fast iterative protein sequence searching by HMM-HMM alignment. Nat Methods 2012, 9, 173-175.

40. Benkert, P., Biasini, M., Schwede, T. Toward the estimation of the absolute quality of individual protein structure models. Bioinformatics 2011, 27, 343-350.

41. Bertoni, M., Kiefer, F., Biasini, M., Bordoli, L., Schwede, T. Modeling protein quaternary structure of homo- and hetero-oligomers beyond binary interactions by homology. Scientific Reports 2017, 7, 10480. 